A tomic

\title{
Advances of Synchrotron Radiation-based Radiometallomics for the Study of Uranium
}

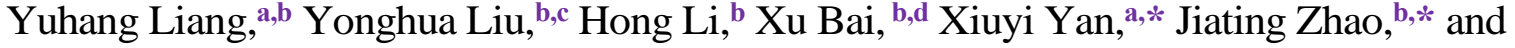 \\ Yuxi Gao ${ }^{\text {b }}$ \\ ${ }^{a}$ College of Chemical Engineering and Environment, China University of Petroleum-Beijing, Beijing 102249, P.R. China \\ ${ }^{\mathrm{b}}$ CAS-HKU Joint Laboratory of Metallomics on Health and Environment, and CAS Key Laboratory for Biomedical Effects of Nanomaterials and \\ Nanosafety, Institute of High Energy Physics, Chinese Academy of Sciences, Beijing 100049, P.R. China \\ ${ }^{\mathrm{c}}$ Taiyuan University of Science and Technology, School of Chemical and Biological Engineering, Shanxi 030000, P.R. China \\ ${ }^{\mathrm{d}}$ University of Chinese Academy of Sciences, Beijing 100049, P.R. China
}

Received: February 27, 2021; Revised: April 02, 2021; Accepted: April 04, 2021; Available online: April 13, 2021.

DOI: $10.46770 / A S .2021 .105$

ABSTRACT: Uranium $(U)$ is one of the most concerned radioactive metals on earth. Thus, to unravel the transportation and transformation of $U$ in the food webs, and tracing its ecological and health risks are of utmost and timely importance. Radiometallomics, in conjunction with the research methods, mainly focus on establishing the ecological and biological metabolisms and behaviors of radiometals/metalloids. In particular, synchrotron radiation (SR) has many advanced properties, e.g., high brightness and collimation, and a wide energy spectrum, which make it a unique technique in the study of metal distribution and speciation analysis. To date, SR-based techniques are widely applied in the environmental sciences; however, a systematic summary of its application in radiometallomics is still lacking. This review assembled and compared the conventional and advanced techniques, especially SR-based radiometallomics used in studying $U$ in environmental matrixes, with the aim that this information will help to develop further combined metallomics approaches in the $\mathrm{U}$ analysis and risk assessment of contaminated areas.

\section{INTRODUCTION}

Uranium $(\mathrm{U})$ is widely distributed in the environment, usually coexisting with other metal compounds or oxides in soils, oceans, rivers and lakes, and various animals and plants. In the earth's crust, the abundance of $U$ is $2.3 \mu \mathrm{g} / \mathrm{g}$, and the natural content of $U$ is usually related to the properties of the rocks and the soil types in the environment. As one of the three important natural radionuclides, $\mathrm{U}$ has three isotopes, ${ }^{234} \mathrm{U},{ }^{235} \mathrm{U}$, and ${ }^{238} \mathrm{U}$, with a natural abundance of roughly $0.0055 \%, 0.7200 \%$, and $99.2745 \%$, respectively. ${ }^{1}$

Uranium is of global concern due to its ecological and human health risks. The hazards of $U$ come from both its radioactivity and heavy metal properties. ${ }^{2}$ Long-term chronic radiation exposure can cause cell damage and chromosomal variation, which leads to changes in the genetic structure. ${ }^{3}$ As the decay products of ${ }^{238} \mathrm{U}$, high concentrations of ${ }^{210} \mathrm{~Pb}$ and ${ }^{210} \mathrm{Po}$ were found in the local vegetables grown in a $\mathrm{U}$ mining area in Cameroon. ${ }^{4}$ Besides, high activity of ${ }^{40} \mathrm{~K}$, which was more than 2 -fold the world average, was also found in the soil, bringing about $5.2 \mathrm{mSv}$ of total radiation to the residents per year. ${ }^{4}$

The half-lives of the three $U$ isotopes are $2.455 \times 10^{5}, 7.038 \times 10^{8}$, and $4.468 \times 10^{9}$ years, respectively. ${ }^{5}$ This extremely long half-life makes it difficult to eliminate its radioactive hazards naturally. Compared with its radioactive dangers, however, the heavy metal toxicity induced by $\mathrm{U}$ is more important and detrimental to the ecology and human health. ${ }^{6}$ For instance, chronic intake of Ucontaining water significantly affects the kidney's reabsorption 
function. ${ }^{7}$ In addition, the calcium ions in the bones are prone to be substituted by $U,{ }^{8}$ and thus the content of $U$ in bones can be used as an important indicator of long-term $U$ exposure, especially in drinking water. ${ }^{9}$ Given the high toxicity of $U$ and its derivatives, the U.S. Environmental Protection Agency (EPA) recommends that the $\mathrm{U}$ concentration in drinking water should not exceed 20 $\mu \mathrm{g} / \mathrm{L} .{ }^{10}$

Thus far, the urgent need to alleviate the ecological and biological impact of $U$ has been recognized, and many studies have been carried out aiming to reduce $U$ pollution in water and soil. However, studies on the translocation, transformation, and accumulation of $U$ in the food chains are rarely reported. Moreover, a systematic summary of the analytical methods commonly used in $U$ analysis to reveal its migration and accumulation under different environmental conditions is still lacking.

Metallomics approaches related to the conventional (e.g. ICPMS, AFS) and advanced elemental analysis technologies (e.g., synchrotron radiation-based techniques) are powerful in revealing the interactions and functional connections of metallic/metalloid elements with regard to the genes, proteins, metabolites, and many other biomolecules within the organisms. ${ }^{11,12}$ SR-based techniques, one of the most important metallomics approaches, are of high significance in studying in situ distribution and speciation of various elements, including $U$. The SR source with a wide frequency range, high brightness, and pulse emission, is superior to traditional light sources. Besides, the SR light is highly polarized, adjustable, and collimated, and can be focused on micro areas. ${ }^{13}$ This article mainly reviews the conventional and advanced techniques usually used in $\mathrm{U}$ analysis, and summarizes the advantages and disadvantages of both the traditional and the SRbased technologies in studying the ecological and biological behaviors of $U$ in different environments (Fig. 1). The study will also show the importance of applying and developing combined radiometallomics approaches for $\mathrm{U}$ analysis and risk assessment in contaminated areas.

\section{ANALYTICAL METHODS FOR U ANALYSIS IN ENVIRONMENTAL AND BIOLOGICAL MATRICES}

The concentration, distribution, speciation, and bonding forms with ligands of $U$ are closely associated with its toxicity. To establish the ecological and biological impact of $U$ and its derivatives, many researchers studied the environmental behavior of $U$ by applying conventional and advanced technologies.

\section{Conventional analytical techniques}

The dose-effect is crucial for almost all hazardous materials in their toxicity. A variety of qualitative and quantitative methods for $\mathrm{U}$ analysis have been established to date. Spectroscopy, chromatography, and mass spectrometry are the most popular approaches for the determination of $U$ in environmental samples. In addition, spectrophotometry as a simple and convenient method is also commonly used. According to the linear relationship between the different concentrations of $U$ and the absorbance, the

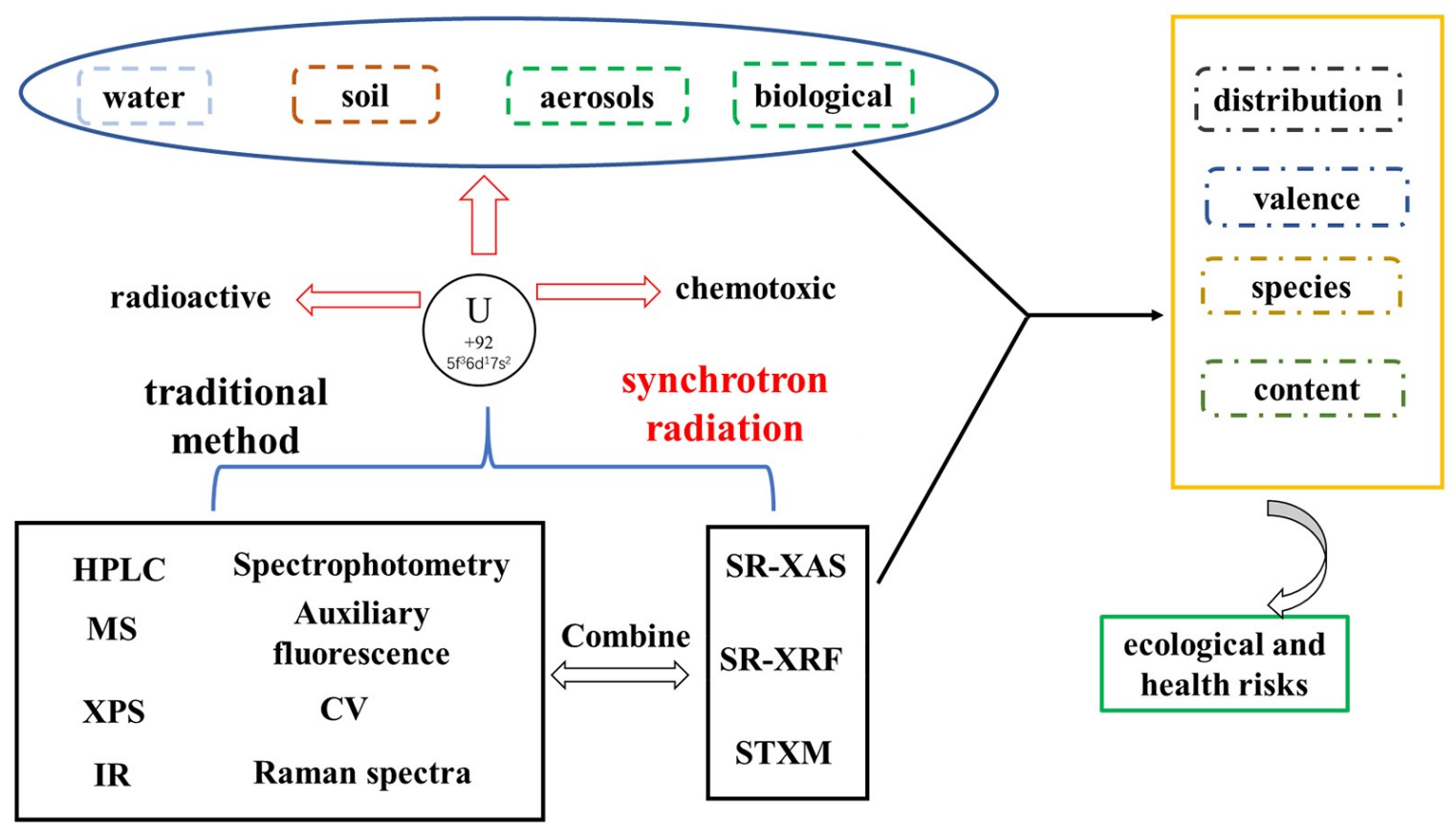

Fig. 1 Analytical approaches in the analysis of U in different environmental matrices. 
quantification of $U$ can be roughly estimated. However, high enrichment of the elements is always necessary to obtain valid data for complex samples, which is time-consuming and often a waste of samples. ${ }^{14,15}$

Based on the color changes between $U$ and the different substances by adding complexing agents, some researchers established a relatively high-resolution spectrophotometric method making the detection limit at ppm levels. For instance, the use of phosphoric acid realizes the determination of $U$ in the lithium chloride-potassium chloride salt matrix, reaching a detection limit of $25 \mathrm{ppm}^{16}$ Moreover, the use of 3aminomethylalizarn-N-N diacetic acid chromogenic dye (AMADA) achieves a detection limit of $0.16 \mu \mathrm{g} / \mathrm{L}$ for $\mathrm{U}$ in water. ${ }^{17}$ The principle of the fluorescence method is to detect $U$ through different fluorescence intensities. Similar to spectrophotometry, impurity ions in a complex matrix will affect the fluorescence intensities. Therefore, enhancing the fluorescence reaction is of importance for $\mathrm{U}$ detection, such as the reaction of $\mathrm{NH}_{4} \mathrm{HF}_{2}$ with boric acid or the use of aluminum nitrate as a salting-out agent. ${ }^{18,19}$

High-performance liquid chromatography (HPLC) with a highpressure infusion system has the advantages of fast analytical speed and low detection limits ( $\mu \mathrm{g} / \mathrm{L}$ levels). Researchers achieved a one-minute separation of U-Th and a 4-minute separation of UPu using HPLC. The high efficiency of a chromatographic column is crucial for chromatography, but the certain "extra-column effects" will lower the column efficiency. ${ }^{20}$ Besides, appropriate chelating agents and elution parameters are also necessary. $U$ in seawater was determined after optimizing the elution parameters, and $\alpha$-hydroxyisobutyric acid was used as a chelator instead of mandelic acid to avoid column blockage due to the high iron content, with a linear range of $0.5 \mathrm{ppb}$ to $500 \mathrm{ppb}^{21}$

ICP-MS is an effective and the most commonly used method for $\mathrm{U}$ analysis with high sensitivity and low detection limits, and is widely used in the quantitative analysis of $\mathrm{U}$ in rock, ${ }^{22}$ soil, ${ }^{23}$ and biological samples, ${ }^{24}$ with the detection limit of $0.1 \mathrm{ng} / \mathrm{kg} .{ }^{25} \mathrm{ICP}-$ MS can also be used to determine the relative ratios of $U$ isotopes. ${ }^{26}$ However, ICP-MS is not suitable for high salinity sample analysis, because excessive salt deposition will shorten the instrument's life and reduce the sensitivity. ${ }^{27}$

The toxicity of $\mathrm{U}$ is closely associated with its valence state. Xray photoelectron spectroscopy (XPS) based on the photoelectric effect cannot only detect the chemical composition of the surface of a sample but also determine the chemical valence state of the element, ${ }^{28}$ which makes it an important approach for $U$ valence analysis. Numerous experiments have proved the feasibility of XPS to study the chemical valence state of U. For example, measurement of mixed-valence U germanate synthesized at high temperature and high pressure by XPS showed the exact peak area ratio of $\mathrm{U}(\mathrm{IV})$ to $\mathrm{U}(\mathrm{VI}) .{ }^{29}$ Another experiment verified that the valence state in the synthesized pyrochlore glass-ceramics was a mixture of U(IV) and U(VI) ${ }^{30}$ Although XPS can perform qualitative, quantitative, and chemical state analysis of elements with high sensitivity, conventional XPS can only reach the $\mathrm{mm}^{2}$ level to obtain average analytical data. Moreover, the energy resolution of XPS is poor due to a non-monochromatic X-ray excitation source.

Electrochemistry is an alternative method in measuring the valence state of elements. Cyclic voltammetry (CV) can be used to study the electrochemical properties of $U$ and investigate the change of the $U$ valence state during electrodeposition. ${ }^{31}$ This approach can also study the single-electron reduction process of $\mathrm{U}(\mathrm{VI})$ to $\mathrm{U}(\mathrm{V})$ by the electrochemical spectrum. ${ }^{32}$ The electrochemical method is relatively simple and convenient. However, it should be noted that it is based on the principle of electrochemistry with relatively more restrictions on sample preparation.

The periodically arranged atomic structure can be an X-ray diffraction grating, that is why X-Ray diffraction (XRD) can be used in phase analysis and crystallinity determination to study the microstructure of matter. XRD was used to obtain the phase properties of the samples, such as $\mathrm{UC}_{2}$ and $\mathrm{U}_{2} \mathrm{C}_{3}$ whose spectrum shows a tetragonal structure, and indicated that the synthesis method can directly influence the single-phase $U$ dicarbide in the composition area. ${ }^{33}$ XRD measurements confirmed the singlephase formation of U-doped alkaline-earth borophosphate samples when preparing them through conventional solid-state reaction routes. ${ }^{34}$

The Raman and IR (Infrared) spectra are also commonly used for U-containing compound structure analysis. Different substances, such as various crystal forms of $\mathrm{UO}_{3}$, have their own unique infrared absorption spectra. ${ }^{35}$ The structure of the glass was found to be significantly changed with introducing a high content of $\mathrm{UO}_{3}$ when studied by IR and Raman spectroscopy. ${ }^{36}$ In comparison, infrared spectroscopy is more sensitive to polar groups by detecting changes in the dipole moment caused by molecular vibrations, while Raman spectroscopy is more sensitive to molecular morphology and often corresponds to non-polar groups. The combination of these approaches is more effective for determining the structure.

In short, there have been a variety of analytical methods for the detection and analysis of $U$ in environmental samples. Considering the requirements for high accuracy, the application of these conventional techniques in $\mathrm{U}$ analysis in complex specimens is quite limited. Meanwhile, due to the complex matrices in the actual ecosystems, pretreatment processes such as separation and enrichment of $U$ in samples before detection are challenging to obtain high precision and accuracy. Fortunately, new research ideas and advanced techniques are constantly emerging and play important roles for the analysis of $U$ in the environment, such as synchrotron radiation (SR)-based technology. 


\section{Synchrotron radiation-based Radiometallomics techniques}

X-rays can be focused to the submicron or even nanometer level, thus having microscopic analysis ability and providing twodimensional information makes it an ideal method for studying the spatial distribution and relative concentration of trace elements. ${ }^{37}$ In situ nondestructive analysis is another advantage with the SRbased technology. ${ }^{38}$ In particular, based on the synchrotron radiation facility, a high-resolution spectrum is expected due to the high brightness, wide wave band, narrow pulse, and high purity light source. Synchrotron radiation X-ray absorption spectroscopy (SR-XAS), synchrotron radiation X-ray fluorescence spectroscopy (SR-XRF), and scanning transmission X-ray microscopy (STXM) are the most commonly used SR techniques for heavy metals analysis. Different electronic structures have variable atomic absorption and transition energies, which can be used for the characterization of the target elements. ${ }^{39}$ The XAS spectrum can be divided into X-ray absorption near edge structure (XANES) and extended x-ray absorption fine structure (EXAFS). XANES gives information on the microstructure and valence state of the surrounding atoms of the target element in crystalline, amorphous, liquid, solid, or even gas materials. ${ }^{40,41}$ EXAFS can provide information including the coordination number, bond length, and bond angle of the target atom with the coordination atoms. In contrast, SR-XRF can perform in situ, microarea, and trace analysis, and realize the simultaneous measurement of multiple elements in one test. ${ }^{42}$ STXM is a microscopic analysis technology with nanometer-level spatial resolution, which has been widely applied in physics, materials, biology, and environmental science. ${ }^{43-45}$ Due to the difference of elements on the absorption edge, the microarea imaging, molecular morphology, and microstructure of the target element in samples can be obtained.

At present, waste discharged from smelting is the main source of $\mathrm{U}$ into the environment. It is distributed in various environmental media through migration and transformation, causing ecological and human health risks. Understanding the concentration, valence state, and distribution of $U$ in an environmental or biological sample is of benefit for subsequent risk assessment and remediation. ${ }^{46}$ SR-based technology can execute the above analysis for $\mathrm{U}$ detection in specimens and avoid sample destruction as otherwise would be required by conventional methods.

\section{SR-XAS}

SR-XANES has been widely used in the analysis of the microstructure and valence states of $U$. When studying $U$ silicate with a mixed valence, researchers determine the valence state of $\mathrm{U}$ and distinguish the major substances in the mixture with the application of SR-XANES (Fig. 2). ${ }^{47}$ Some researchers used SRXANES to judge the valence state of $U$ in fuel fragments which indicated that the oxidation state of $\mathrm{U}$ in $\mathrm{CrUO}_{4}$ and $\left(\mathrm{Fe}_{\mathrm{x}}\right.$, $\left.\mathrm{Cr}_{1-\mathrm{x}}\right) \mathrm{UO}_{4}$ was pentavalent. ${ }^{48}$ The frequent use of large amounts of depleted $U$ munitions in some conflict areas has resulted in the presence of $U$ at a certain level in the local environment. Therefore, U-containing particles should be considered in assessing the local environmental and health risks. Researchers analyzed the $U$ in the soil of the Kosovo Sega Mountains using XANES, half of which was in the form of $\mathrm{UO}_{2}$, and the others were $\mathrm{U}_{3} \mathrm{O}_{8}$ or a mixture of the two species. This finding provided information for further assessing the environmental risks induced by $\mathrm{U}^{49}$

In addition, the change in the valence state of $U$ is also related to microorganisms. For instance, the life activities of microorganisms can reduce soluble U(VI) to insoluble U(IV), which is generally used as a remediation method for U(VI)containing groundwater. Researches mixed U-contaminated
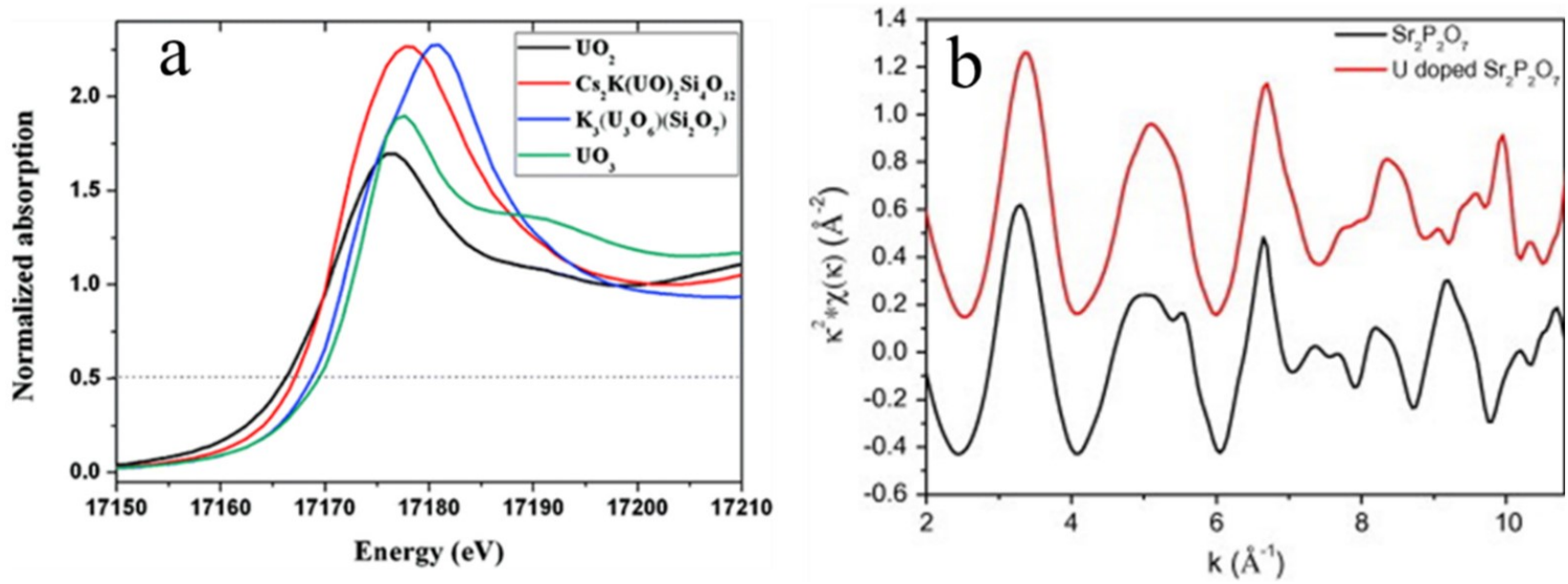

Fig. 2 Application of SR-XAS in the study of the valence and structure of $U$ containing specimens. (a) U L3-edge XANES spectra of several U substances. The dotted line at the absorption coefficient value of 0.5 is included to elucidate the chemical shift; ${ }^{47}$ (b) EXAFS spectra in $\mathrm{k}$ space for pure $\mathrm{Sr}_{2} \mathrm{P}_{2} \mathrm{O}_{7}$ and $\mathrm{U}$ doped $\mathrm{Sr}_{2} \mathrm{P}_{2} \mathrm{O}_{7}{ }^{54}$ 
sediment with water and added nutrients to stimulate the growth of indigenous microorganisms. The concentration of $U$ in groundwater dropped from $20 \mathrm{ppm}$ to $0.3 \mathrm{ppm}$ within one month. XANES results showed that most of the $\mathrm{U}$ is reduced to $\mathrm{U}(\mathrm{IV}) .^{50}$

Apart from the determination of valence state, qualitative analysis of $U$ has also been executed by SR-XANES in some cases. Martin et al. ${ }^{51}$ confirmed and semi-quantified $U$ being present in the surface soils from 35 kilometers northwest of the nuclear power plant by XANES. By comparing the size of U material, it is inferred that $\mathrm{U}$ may come from the Fukushima nuclear power plant.

In contrast to SR-XANES, SR-EXAFS has the advantages of revealing the atomic morphology and regional structure, which can be combined with $\mathrm{XRD}^{33}$ and $\mathrm{IR}^{52}$ to observe the microstructure of matter. U-containing compounds with different valences, including $\mathrm{U}^{4+}, \mathrm{U}^{5+}$, and $\mathrm{U}^{6+}$, have different chemical shifts at the L3 edge of U. The measurements carried out at the energy-dispersive EXAFS beamline uncovered that the U L3 edges in the compounds were shifted by $2-3 \mathrm{eV}$ compared to that of elemental U. Moreover, the U L3 edge energy was found to be shifted by different amounts in many compounds due to the various chemical environments around the $U$ cation. ${ }^{53}$ When studying the morphology and structure of the $U$ atoms in strontium pyrophosphate, $U$ existed in two different positions in the form of uranyl. The EXAFS spectrum revealed that on doping with $\mathrm{U}$, the average $\mathrm{Sr}-\mathrm{O}$ and $\mathrm{Sr}-\mathrm{P}$ bond lengths increased (Fig. 2) ${ }^{54}$ Based on the study of luminescence lifetime and EXAFS data, it was inferred that uranyl is stable on 9- and 10-coordinated strontium polyhedral. 9-coordinated strontium sites are relatively asymmetric and the position is occupied by mostly uranyl. ${ }^{55}$

Tracing the migration of $U$ in a contaminated area is of great significance to control pollution. The presence of phosphate has a certain effect on the reduction of U. Some studies used EXAFS to prove that the environment with high phosphate and low $\mathrm{pH}$ can inhibit the reduction of U(VI) to U(IV), and uranyl phosphate can form by co-precipitation under the condition of high phosphate. ${ }^{56}$ The presence of soluble silicate can affect the adsorption of U(VI) on other substances. It is confirmed by batch experiments and EXAFS that the presence of silicate enhanced the adsorption of $\mathrm{U}(\mathrm{VI})$ on $\gamma-\mathrm{Al}_{2} \mathrm{O}_{3}$, which contributed to the formation of ternary inner-sphere surface complex and acted as a bridge between both matters. ${ }^{57}$

\section{SR-XRF}

SR-XRF is an advanced elemental analysis method with high spatial resolution and sensitivity, and has certain applications in analyzing the composition of matter and studying the basic properties of atoms. $U$ exists in contaminated soils in many forms, commonly as U(VI) and U(IV) and varies with different distributions. Some researchers ${ }^{58}$ analyzed the element species and their spatial distributions in four soils by SR-XRF to determine whether the presence of $\mathrm{U}$ in soils is correlated with other elements The SR-XRF spectrum showed that there was no obvious adsorption or co-precipitation between $U$ and iron, titanium, manganese, and silicon, suggesting no obvious correlation among them. However, $U$ was expected to be coordinated with organic matter, similar to other heavy metals. ${ }^{58} \mathrm{SR}$ (micro) $\mu$-XRF was also used to image the distribution of $U$ in limestone (Fig. 3a). The selected $U$ concentrated sites were then scanned with XANES for the species analysis of $U$. Meanwhile, SR $\mu$-XRF mapping confirmed the coexistence of $U$ with organic matter in the same part of the specimen. The researchers believed that there should be a positive correlation between $U$ and phosphorus. The $U$ was identified mainly as the oxidation state of U(IV). Data from XANES indicated the presence of U(IV) associated with apatitelike minerals and/or organics. ${ }^{59}$

The SR-XRF technology can also be used to trace the source and predict environmental changes by unraveling the distribution of elements. Studying $U$ in aerosols is an ideal approach to trace the pollution sources in soil and water. Researchers ${ }^{60}$ analyzed the elemental distribution of aerosols in the snow of Novosibirsk using SR-XRF and established that $U$ was discharged into the surrounding area in a dispersed form from the local chemical factories, mainly in the form of particles of a mixture with $U$ oxide, iron, and copper. The adsorption of $U$ by aero-aluminosilicate particles may cause long-distance migration of $U$. This study also revealed that only a small amount of aerosol $U$ was discharged from the surrounding thermal power plants. ${ }^{60}$ SR-based highresolution scanning X-ray fluorescence technology was used to map the distribution of $U$ and its isotopes in Lake Baikal and Lake Tretzkoye, establishing the physical models of river runoff to predict future climate change and reproduce the past water and heat conditions of typical regions. ${ }^{61}$ Compared with environmental samples, $\mathrm{U}$ in organisms is more likely to attract people's attention. Exploring the distribution of $U$ in biological samples is of great significance to understand the hazards of U. In this regard, SR-XRF has broad application prospects. In order to better evaluate the toxic effects of $U$ on human bodies, a large number of animal research has been carried out. Kidneys are critical targets for $U$ exposure. The impact of $U$ on the health of animals and human beings is mainly reflected in the nephrotoxicity. ${ }^{62} \mathrm{U}$ accumulation in the proximal tubule and damage of site-specific tissue are two typical characteristics of $U$ nephrotoxicity. ${ }^{63}$ In comparison to the traditional analytical methods, SR-based technology plays an important role in obtaining information of the U species and their in situ microdistribution in the tissues and organs. Researchers ${ }^{64}$ analyzed $U$ in the kidneys of adult mice pre-exposed to uranyl acetate with the help of SR-XRF method. After subcutaneous injection of $2 \mathrm{mg} / \mathrm{kg}$ of uranyl acetate, the $U$ in the kidney peaked after one day and then decreased. The renal distribution of $U$ is site-selective and site-specific renal damage is caused. After 3 hours of exposure, $U$ mainly distributed in the proximal tubules of the inner cortex and 
a
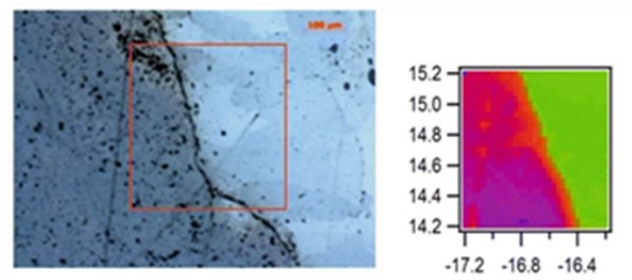

FLUO [mm]
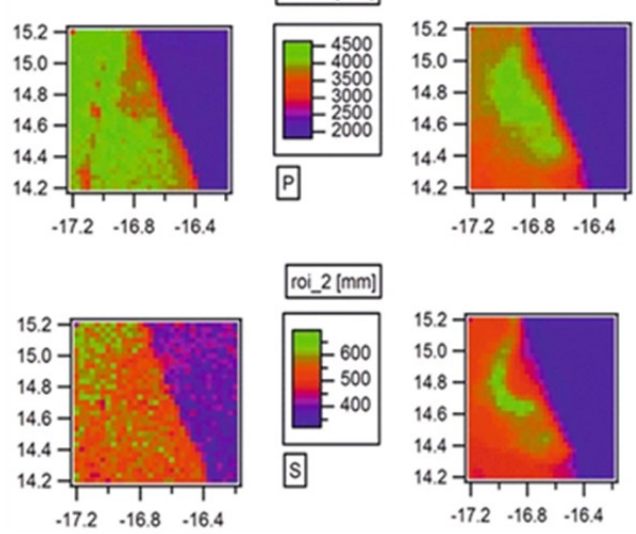
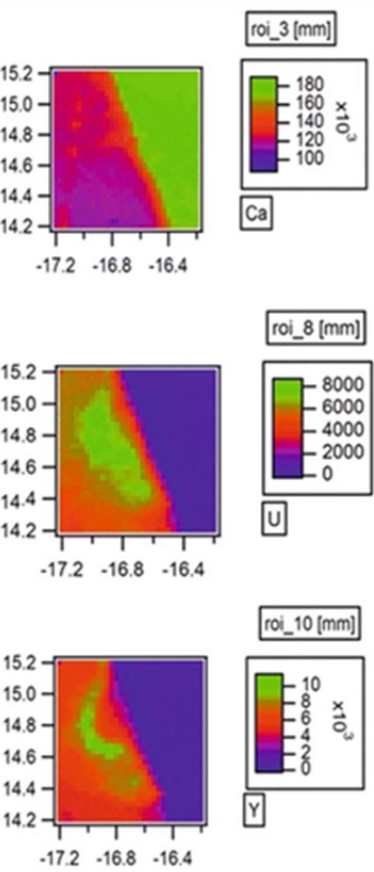
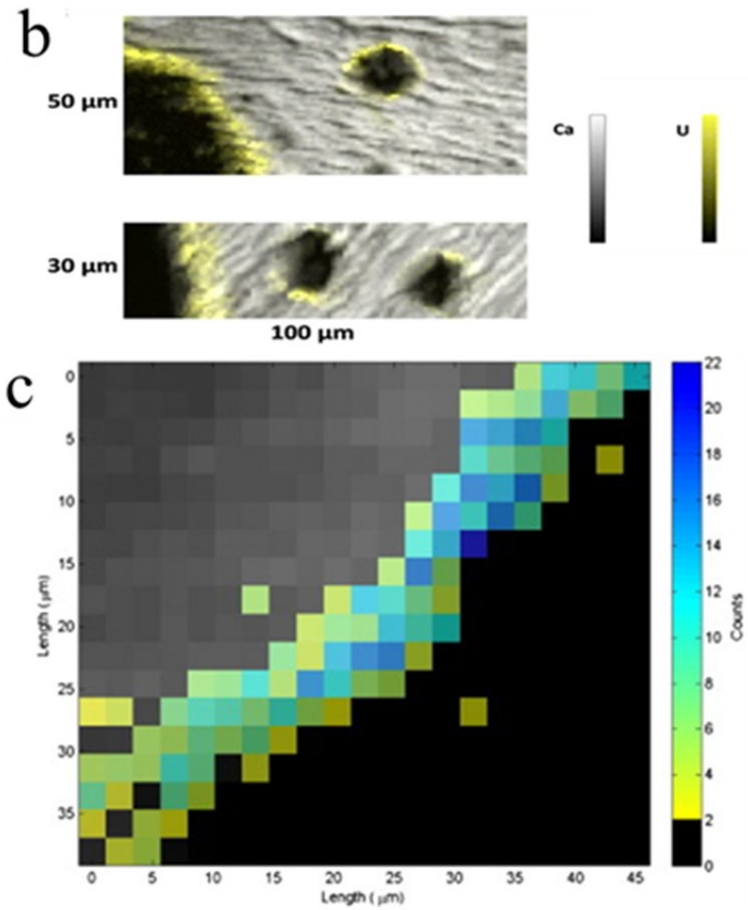

Fig. 3 SR-XRF applications in U measurement in environmental and biological specimens. (a) Optical image of the polished section of the U-bearing limestone (upper left) and qualitative SR $\mu$-XRF elemental maps. The dark side corresponds to the organic-rich component, where (U and P) is mostly accumulated, while the bright site to Ca-carbonate, ${ }^{59}$ (b) High-resolution $\left(1 \times 1 \mu \mathrm{m}^{2}\right)$ elemental distribution of Ca (light gray) and $\mathrm{U}$ (yellow) at the edge of the cortical bone and around blood vessel canals of rats (transversal 8 - $\mu$ m-thick section) by SR-XRF; ${ }^{.7}$ (c) Bitmap representation of a quarter of the full cross section of a hair shaft with SR confocal $\mu$-XRF. The $U \mathrm{~L}_{\alpha}$ intensity map (yellow/blue scale) is superimposed on the zinc $\mathrm{K}_{\alpha}$ map (gray scale) with white and blue indicating higher signals. The hair shaft was unwashed and was sampled from the worker at a nuclear fuel fabrication plant. ${ }^{68}$

the outer medulla, absorbed by the epithelium of the proximal tubule. Apoptosis of the epithelial cells of the proximal tubule occurred within 3 days, and $U$ was mainly detected in the outer medulla after 15 days. ${ }^{64}$ Besides, the biotransformation of $U$ mainly occurred in the epithelium of the proximal tubule determined by two-dimensional XAFS, and it was independent of the U level. ${ }^{62}$ Some studies suggested that oxidative stress should be a key response to U-induced kidney damage. ${ }^{65,66}$

Age and exposure level are important parameters of $U$ toxicity. Low-level U exposure can cause long-term U existence, and more obvious nephrotoxicity was found occurring in adult rats. ${ }^{63} \mathrm{In}$ addition, damage to animal bones induced by $U$ cannot be ignored. However, it is really hard to detect $U$ in bones using traditional methods because of the generally low content of $U$ in bones. SR$\mathrm{XRF}$ is an ideal approach which is successfully applied to $U$ analysis in animal bones. The experiments of $U$ exposure in rats showed that $U$ preferentially concentrated in the calcified areas of the bones, and accumulated rapidly in the femoral metaphysis and newly formed trabecular bone tissue (Fig. 3b) ${ }^{67}$ Moreover, U can accumulate and be stored in hair, which makes it a biological indicator for $U$ exposure. SR-XRF can detect $U$ at the fg level and show its distribution in a single hair. For instance, Fig 3c shows that $U$ can been seen mainly distributed in the $10-15 \mu$ m outer layer of the hair. ${ }^{68}$

\section{STXM}

STXM has the capability of elemental identification, chemical states and micro-distribution analysis of elements with low resolution up to $30 \mathrm{~nm} .{ }^{69}$ When studying the adsorption of U(IV) in sediments using STXM, researchers observed the formation of carbon-combined species in the U-rich region. Meanwhile, with the help of EXAFS and nanosecondary ion mass spectrometry, it showed that under sulfate reduction conditions, U(IV) was adsorbed to particulate organic carbon (POC) and organic mattercoated clays in $\mathrm{U}$ contaminated areas. ${ }^{70}$ By comparing the ability of three humic acids to co-transport U(VI) in the water-saturated sand column, the distribution pattern of carbon and $U$ presented by STXM measurement indicated the heterogeneity in microscopic distribution of $U$ in the samples. It provided direct evidence that hydrophobic organic matter plays a key role in the binding and migration of HAs and $U$ in the natural environment. ${ }^{71}$

\section{CONCLUSIONS AND PERSPECTIVES}

The transportation and accumulation of radioactive metallic elements in food webs can raise radiation damage and heavy metal pollution in the environment, posing health risks to human beings. 
To date, there have already been many works focused on developing novel materials to alleviate radioactive pollution in the water systems. However, there is still a lack of research which can completely reveal the transportation and transformation of radioactive metallic elements, e.g. $\mathrm{U}$, in the food chains, and trace their ecological and health risks in complex environments. In this study, we put forward the concept of "radiometallomics", which mainly focuses on unraveling the ecological and biological metabolisms and behaviors of radioactive metal elements, and discuss the traditional and advanced technologies used for this study, with the aim to promote future research in this field.

Traditional methods, such as ICP-MS, XPS, XRD, etc., can meet certain needs in the analysis and determination of the concentration, valence and structure of $U$, but their lower resolution and high requirement for pretreatment limit their application. In comparison to the traditional methods, the SRbased technology has unique advantages and has been increasingly applied for radioactive metals analysis. This technology can give information on the elemental species, valence state, and the in situ micro-distribution and speciation of $U$ in complex environments with high precision, providing more reliable and convenient methods for radiometallomics research.

From the published works, the SR-based technology has played an important role in the measurement of $U$ in soil, water, and organisms. However, the three main factors hindering the individual application of SR-based techniques in $U$ analysis for environmental and biological samples include: (a) lack of synchrotron radiation facilities around the world (only approximately 60 SR facilities globally), (b) sample collection is very time-consuming and labor-intensive, and (c) the requirement for high resolution for $\mathrm{U}$ analysis. Since both the traditional and SR-based technologies have their advantages and disadvantages, it is the hope that in the near future the combined application of several approaches will effectively lead to uncover the biogeochemical behavior of $\mathrm{U}$ in complex environments and thus, develop new analytical methods to alleviate $U$ toxicity and remediate U-contaminated fields.

\section{AUTHOR INFORMATION}

\section{Corresponding Authors}

${ }^{*}$ X. Y. Yan

Email address: yanxiuyi@cup.edu.cn

* J. T. Zhao

Email address: zhaojt@ihep.ac.cn

\section{Notes}

The authors declare no competing financial interest.

\section{ACKNOWLEDGMENTS}

This work was financially supported by the Natural Science Foundation of China (U2032201, 21777162). We thank the BSRF (beamline 4W1B and 1W1B) and the SSRF (BL15U and BL14W) for beam time allocation and technical assistance.

\section{REFERENCES}

1. Y. N. Vodyanitskii, Eurasian Soil Sci., 2011, 44, 862-873. http://dx.doi.org/10.1134/S1064229311080163

2. S. Garboś and D. Święcicka, Arch. Environ. Prot., 2015, 41, 21-27. http://dx.doi.org/10.1515/aep-2015-0014

3. S. A. Geraskin, V. G. Dikarev, and Y. Y. Zyablitskaya, J. Environ. Radioactiv., 2003, 66, 155-169. https://doi.org/10.1016/S0265-931X(02)00121-2

4. Saïdou, F. O. Bochud, and S. Baechler, Radiat. Meas., 2011, 46, 254-260. http://dx.doi.org/10.1016/j.radmeas.2010.11.009

5. G. Bjorklund, Y. Semenova, and L. Pivina, Arch. Toxicol., 2020, 94, 1551-1560. https://doi.org/10.1007/s00204-020-02676-8

6. A. Rump, S. Eder, and A. Lamkowski, Toxicol. Lett., 2019, 313, 159-168. http://dx.doi.org/10.1016/j.toxlet.2019.07.004

7. M. L. L. Zamora, J. M. Zielinski, and G. B. Moodie, Arch. Environ. Occup. Health., 2009, 64, 228-241. http://dx.doi.org/10.1080/19338240903241267

8. R. Shelley, N. S. Kim, and P. J. Parsons, J. Expo. Sci. Environ. Epidemiol., 2014, 24, 58-64. https://doi.org/10.1038/jes.2013.18

9. D. Lariviere, S. Y. Tolmachev, and V. Kochermin, J. Environ. Radioact., 2013, 121, 98-103. http://dx.doi.org/10.1016/j.jenvrad.2012.05.026

10. USEPA. EPA integrated risk information system (IRIS) electronic database. Washington, DC, 1996.

11. H. Haraguchi, J. Anal. At. Spectrom. 2004, 19, 5-14. http://dx.doi.org/10.1039/B308213J

12. Y. Li, J. Zhao, and Y. F. Li, Metallomics, 2016, 8, 663-671. https://doi.org/10.1039/c5mt00264h

13. Y. F. Li, J. Zhao, and Y. Gao, Synchrotron Radiation in Materials Science. 2018. http://dx.doi.org/10.1002/9783527697106.ch15

14. K. Oguma, T. Suzuki and K. Saito, Talanta, 2011, 84, 1209-1214. http://dx.doi.org/10.1016/j.talanta.2010.12.020

15. V. V. Kuznetsov, S. V. Zemyatova and K. A. Kornev, J. Anal. Chem., 2014, 69, 105-110. http://dx.doi.org/10.1134/S106193481312006X

16. S. Kumar, S. Maji, and K. Sundararajan, J. Radioanal. Nucl. Chem., 2019, 320, 337-343. http://dx.doi.org/10.1007/s10967-019-06471-3

17. A. H. Orabi, N. I. Falila, and D. A. Ismaiel, J. Radioanal. Nucl. Chem., 2020, https://doi.org/10.1007/s10967-020-07496-9

18. B. K. Balaji, A Premadas, and G. V. Ramanaiah. Talanta, 1984, 31, 846-847. http://dx.doi.org/10.1016/0039-9140(84)80209-X

19. S. K. Pradhan and B. Ambade, J. Radioanal. Nucl. Chem., 2019, 320, 459-466. https://doi.org/10.1007/s10967-019-06468-y

20. M. Ravichandran, Chemosphere, 2004, 55, 319-331. https://doi.org/10.1016/j.chemosphere.2003.11.011

21. P.G. Jaison, V. M. Telmore, and P. Kumar, J. Chromatogr. Sci., 2011, 49, 657-664. http://dx.doi.org/10.1093/chrsci/49.9.657 
22. M. R. Khattab, H. Tuovinen, and J. Lehto, Instrument. Sci. Technol., 2017, 45, 338-348. https://doi.org/10.1080/10739149.2016.1242078

23. G. Proctor, H. Wang, and S. L. Larson, ACS Earth Space Chem., 2020, 4, 211-217. http://dx.doi.org/10.1021/acsearthspacechem.9b00272

24. M. Venus, D. Puntaric, and V. Gvozdic, J. Environ. Radioact., 2019, 203, 147-153. https://doi.org/10.1016/j.jenvrad.2019.03.004

25. Somayeh Veyseh, Ali Niazi, Talanta, 2016, 147, 117-123. https://doi.org/10.1016/j.talanta.2015.09.032

26. H. Jaegler, A. Gourgiotis, and P. Steier, Anal. Chem., 2020, 92 , 7869-7876. http://dx.doi.org/10.1021/acs.analchem.0c01121

27. C. Hein, J. M. Sander and R. Kautenburger, Talanta, 2017, 164, 477-482. https://doi.org/10.1016/j.talanta.2016.06.059

28. B. Jabłoński, S. Pacanowski, and M. Werwiński, Acta Phys. Pol. A, 2018, 133, 620-623. http://dx.doi.org/10.12693/APhysPolA.133.620

29. Q. B. Nguyen, H. K. Liu, and W. J. Chang, Inorg. Chem., 2011, 50, 4241-4243. https://doi.org/10.1021/ic200508v

30. Z. Feng, H. Xie, and L. Wang, Ceram. Inter, 2019, 45, 16999-17005. https://doi.org/10.1016/j.ceramint.2019.05.249

31. S. K. Gupta, N. Pathak, and R. Gupta, J. Mol. Struct., 2014, 1068, 204-209. http://dx.doi.org/10.1016/j.molstruc.2014.04.016

32. K. Yuan, E. S. Ilton, and M. R. Antonio, Environ. Sci. Technol., 2015, 49, 6206-6213. https://doi.org/10.1021/acs.est.5b00025

33. U. C. Nuñez, R. Eloirdi, and D. Prieur, J. Alloy. Compd., 2014, 589, 234-239. https://doi.org/10.1016/j.jallcom.2013.11.202

34. A. Rout, B. S. Panigrahi, and C. Nayak, J. Am. Ceram. Soc., 2017, 100, 2921-2931. http://dx.doi.org/10.1111/jace. 14800

35. M. A. Khilla, S. A. Elfekey, and N. H. Rofail, Radiochim. Acta, 1986, 40, 185-190. http://dx.doi.org/10.1524/ract.1986.40.4.185

36. S. V. Stefanovsky, O. I. Stefanovsky, and M. I. Kadyko, J. Non-Cryst. Solids, 2016, 443, 192-198. http://dx.doi.org/10.1016/j.jnoncrysol.2016.04.031

37. J. Zhao, Y. Pu, and Y. Gao, J. Anal. At. Spectrom., 2015, 30, 1408-1413. http://dx.doi.org/10.1039/C5JA00043B

38. J. Zhao, Y. Li, and Y. Li, Metallomics, 2014, 6, 1951-1957. https://doi.org/10.1039/c4mt00170b

39. E. Lombi and J. Susini, Plant Soil, 2009, 320, 1-35. https://doi.org/10.1007/s11104-008-9876-x

40. K. E. Fletcher, M. I. Boyanov, and S. H. Thomas, Environ. Sci. Technol. 2010, 44, 4705-4709. https://doi.org/10.1021/es903636c

41. H. S. Moon, J. Komlos and P. R. Jaffe, J. Contam. Hydrol, 2009, 105, 18-27. http://dx.doi.org/10.1016/j.jconhyd.2008.10.014

42. Y. Li, J. Zhao, and Y. Li, Scientia Sinica Chimica, 2015, 45, 597-613. http://dx.doi.org/10.1360/N032014-00314

43. A. Templeton and E. Knowles, Annu. Rev. Earth Pl. Sci., 2009, 37, 367-391. https://doi.org/10.1146/annurev.earth.36.031207.124346

44. J. W. Stuckey, J. Yang, and J. Wang, J. Environ. Qual., 2017, 46, 1166-1174. https://doi.org/10.2134/jeq2016.10.0399

45. W. Chao, B. D. Harteneck, and J. A. Liddle, Nature, 2005, 435, 1210-1213. http://dx.doi.org/10.1038/nature03719

46. X. Peng, L. Pei, and M. Min, .U. Geology, 2003, 19, 225-231. http://dx.chinadoi.cn/10.3969/j.issn.1000-0658.2003.04.006

47. C-S. Lee, S-L. Wang, and K-H. Lii, ChemInform, 2009, 131, 511615117. https://doi.org/10.1021/ja9071805
48. D. Akiyama, H. Akiyama, and A Uehara, J. Nucl. Mater, 2019. 520, 27-33. https://doi.org/10.1016/j.jnucmat.2019.03.055

49. B. Salbu, K. Janssens, and O.C. Lind, J. Environ. Radioactiv., 2003, 64, 167-173. https://doi.org/10.1016/s0265-931x(02)00047-4

50. J. D. Istok, J. M. Senko, and L. R. Krumholz, Environ. Sci. Technol, 2004, 38, 468-475. https://doi.org/10.1021/es034639p

51. P. G. Martin, I. Griffiths, and C. P. Jones, Spectrochim. Acta B, 2016, 117, 1-7. https://doi.org/10.1016/j.sab.2015.12.010

52. O. Pecheur, D. Guillaumont, and S. Dourdain, Solvent Extr Ion Exc., 2016, 34, 260-273. http://dx.doi.org/10.1080/07366299.2016.1169146

53. D. Joseph, C. Nayak, and P. V. Babu, B. Mater. Sci., 2014, 37, 643-647. https://doi.org/10.1007/s12034-014-0679-9

54. M. Mohapatra, A. K. Yadav, and S. N. Jha, Chem. Phys. Lett., 2014, 601, 81-86. https://doi.org/10.1016/j.cplett.2014.03.093

55. S. K. Gupta, A. K. Yadav, and S. Nigam, Spectrochim. Acta A, 2015, 151, 453-458. https://doi.org/10.1016/j.saa.2015.06.058

56. M. Qiu, M. Wang, and Q. Zhao, Chemosphere, 2018, 201, 764-771. https://doi.org/10.1016/j.chemosphere.2018.03.057

57. H. Mei, X. Tan, and S. Yu, Chem. Eng. J., 2015, 269, 371-378. https://doi.org/10.1016/j.cej.2015.01.121

58. M. C. Duff, C. F. V. Mason, and D. B. Hunter, Can. J. Soil Sci, 1998, 78, 675-683. https://doi.org/10.4141/S97-059

59. I. T. Tzifas, U. A. Glasmacher, and P. Misaelides, J. Radioanal. Nucl. Chem., 2016, 311, 465-472. https://doi.org/10.1007/s10967-016-4973-4

60. S. Y. Artamonova, Phys. Procedia, 2016, 84, 280-287. https://doi.org/10.1016/j.phpro.2016.11.048

61. E. L. Goldberg, M. A. Grachev, and E. P. Chebykin, Nucl. Instrum. Meth. A, 2005, 543, 250-254. https://doi.org/10.1016/j.nima.2005.01.216

62. S. Homma-Takeda, A. Uehara, and T. Yoshida, Radiat. Phys. Chem., 2020, 175, 108147. https://doi.org/10.1016/j.radphyschem.2019.02.006

63. S. Homma-Takeda, T. Kokubo, and Y. Terada, J. Appl. Toxicol., 2013, 33, 685-694. https://doi.org/10.1002/jat.2870

64. S. Homma-Takeda, Y. Terada, and A. Nakata, Nucl. Instrum. Meth. B, 2009, 267, 2167-2170. https://doi.org/10.1016/j.nimb.2009.03.082

65. V. Linares, M. Belles, and M. L. Albina, Toxico. Lett., 2006, 167, 152-161. https://doi.org/10.1016/j.toxlet.2006.09.004

66. C. Thiebault, M. Carriere, and S. Milgram, Toxicol. Sci., 2007, 98, 479-487. https://doi.org/10.1093/toxsci/kfm130

67. D. Bourgeois, B. Burt-Pichat, and X. Le Goff, Anal. Bioanal. Chem., 2015, 407, 6619-6625. https://doi.org/10.1007/s00216-015-8835-7

68. A. Israelsson, M. Eriksson, and H. B. L. Pettersson, Spectrochim. Acta B, 2015, 108, 28-34. https://doi.org/10.1016/j.sab.2015.04.001

69. X. Z. Zhang, Z. J. Xu, and R. Z. Tai, J. Synchrotron Radiat., 2010, 17, 804-809. https://doi.org/10.1107/s0909049510031250

70. S. E. Bone, J. J. Dynes, and J. Cliff, Proc. Natl. Acad. Sci. USA, 2017, 114, 711-716. https://doi.org/10.1073/pnas.1611918114

71. Y. Yang, J. E. Saiers, and N. Xu, Environ. Sci. Technol., 2012, 46, 5931-5938. https://doi.org/10.1021/es300155j 